\title{
Food consumption and civil society: Mediterranean diet as a sustainable resource for the Mediterranean area
}

\author{
F Xavier Medina* \\ Department of Food Systems, Culture and Society, Faculty of Health Sciences, Universitat Oberta de Catalunya \\ (UOC), Mediatic UOC Headquarters Roc Boronat, 117 E-08018 Barcelona, Catalonia, Spain
}

Submitted 13 May 2011: Accepted 7 September 2011

\begin{abstract}
Objective: To define the Mediterranean diet model inside a Mediterranean social and cultural food framework and from the perspective of a local model of consumption.

Design: Reflexion and review of literature available in relation to the Mediterranean diet, locality and proximity.

Setting and subjects: Mediterranean region and its populations.

Results: The Mediterranean local food system under the term Mediterranean diet encourages local production and local consumption. From this perspective, this model takes part of every local Mediterranean lifestyles and encourages sustainability.

Conclusions: From a local Mediterranean point of view and as a proximity model of consumption, Mediterranean food and diet can be a sustainable resource for the Mediterranean area.
\end{abstract}

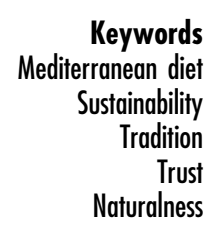

During almost the whole twentieth century, but especially in the second half, transformations in the food field have been increasing. In societies with a higher socioeconomic development, with local markets well provided with food, this has, in general terms, involved a larger production and distribution of products at an industrial level and more fluid access to a large variety of food by the public, at much more accessible prices.

In developing countries, with home economies - and not only home economies - very attached to small production and subsistence agriculture, this process has had very different effects, and not always positive. The reality is that, as the FAO points out ${ }^{(1)}$, one billion people live in chronic hunger globally.

\section{Food knowledge is social and industrial trust}

In developed countries, very well provided, the argument, however, is to the contrary. On the other hand, we find that such production, nowadays more massified and industrialised than ever, has likewise seen itself affected in a different way: by different health problems (diseases, infections, etc.) related to industrial production as well as, and consequently, by a growing mistrust among the population towards the food they consume ${ }^{(2)}$.

In this context, it should also be noted that systems for representing citizens evolve more slowly than production and distribution systems, with technological innovations in products and packaging, places of production and transport, storage and distribution, as well as in relation to other individuals. Consumers have only a partial understanding of these developments, which span the entire period from what might be termed the 'traditional' or 'preindustrial' situation to the present-day era of 'cracking' and 'assembly'. In this pattern of evolution, the role of food manufacturers has changed and food itself is now presented in two ways: on the one hand, it has become more artificial, and on the other, it must retain a certain 'natural' status, as this is the sole tangible nexus with nature for the consumer.

Moreover, given that consumers today now have a much wider range of food flavours to choose from, it is important to consider the fact that they can have no more than a partial knowledge of the variety of tastes and aromas of foods whose organoleptic and microbiological qualities have improved and continue to do so. The time lag between one experience of a particular foodstuff and the next occasion when it is eaten makes it more difficult for people to build up a personal memory bank of different food tastes ${ }^{(3)}$.

On the other hand, changes in food come up against a degree of dissatisfaction on the part of the consumer, who is faced, for example, with 'industrial' foods that he finds bland, lacking in the taste and aroma these foods used to have, and perhaps even dangerous. Thus, nowadays it is impossible not to emphasise the doubts and the feeling of danger connected to the impossibility of control over 
industrial production processes by a broad strata of consumers. In the same way, we are living in times in which urban people - most of the population in industrialised countries - have contact with only end elements of the chain, that is, final points of distribution and products.

This implies that, concerning food, consumers' trust is taken for granted in phases of the process that are absolutely unknown by them, leaving out the ignorance of the processes undertaken by experts, who are entrusted with the control of the different phases of the process that extend from the earliest stages of production to the table, through the factory and the supermarket. The consumer, in short, gets further and further from the food production process and loses control over it as well as information about it. In view of this situation, the public opinion manifests its fears and concerns widely and in different ways. In the words of the North American anthropologist Sydney Mintz ${ }^{(4)}$, 'recent history and mass media are preparing us for an environmental catastrophe. We are willing to discover impurity at every step, willing to be threatened by impurity at every moment'. Unawareness of the mentioned production procedures, of food transformation, makes consumers mistrust the industrial processes and the mediators who create, transform, pack, transport them, etc. One of the most important consequences of this is the increasing attempts by consumers to recover control, to go back, even mentally, to those stages in which things were 'pure', 'healthy', 'authentic' and handmade, made with time... In a 'traditional' way, in short. Much of our longing for what is pure - water, air, vegetables, fruits - looks back yearning for a past more and more on its way to extinction ${ }^{(4)}$. A past that brings in 'quality' and 'naturalness' to an uncertain present. It is not strange, then, that publicity has decided to exploit these aspects broadly, offering 'traditional', 'old style', 'homemade', 'grandmother's' dishes, etc.

Consumers usually sum up their perception of this entire panorama by mentioning notions to do with authenticity and quality, which implies perfect adaptation to their culture and representational system. Food cannot be observed as an isolated element from their cultural framework. Otherwise it can lose all meaning to the extent that it does not seem to be 'real food'.

\section{New strategies}

This trend, this 'search' by consumers for what is natural, hand-crafted, has not gone unnoticed by the different social actors involved in this process: public and private institutions, producers, industrialists, traders, publicists, editors, restaurateurs, tourism promoters... . At the same time that users try to recover control over what they eat, from the other side of the commercial barrier this trend towards what is 'traditional' and 'natural' is reaffirmed. But we cannot forget that, as with every other aspect of cultures, nothing is static, everything is ductile and is in continuous re-elaboration, re-creation. Thus, 'tradition' is built; it is 'created' and 're-created' every day ${ }^{(5)}$. Hence, for example, a strategy that fast-food chains have taken into account in order to guarantee themselves future customers has precisely been that of building customers' loyalty from the time they are children, making them integrate fast-food taste and smell as part of their past, of their personal food tradition. As the North American writer Eric Schlosser ${ }^{(6)}$ points out in relation to fast-food establishments in the USA, 'the flavours of food during childhood seem to leave a permanent mark, and adults usually go back to them without knowing why most of the time. This "soothing food" of childhood becomes a source of pleasure and calmness, an increasing attempt to provide the public in general with broader information about the offered product, information that takes us to its origin', and that points out the 'traditional' and 'handcrafted' elements of it. This is an element that fast-food chains strongly try to provide.

The search for 'traditional', 'authentic' dishes, the appreciation of 'family cooking', old cookbooks, orally transmitted recipes, etc. takes place, very particularly, in a social and historical moment in which the industrial transformation of food increasingly moves consumers of industrialised countries away from the control and knowledge of its production procedures. Going back to what is 'traditional', to the old cooking 'teachings', to things the origin of which is known - including the growth of the importance and of the search for 'bio' products or for ecological products - to those whose transformation procedures are trusted, then becomes a value intimately linked to the enjoyment of cooking as well as to nutrition in general terms. Such an appreciation involves a social demand for these types of products, which has an effect on different social, cultural and economic environments - such as the case of individuals and families, especially those who can afford to place quality before price; 'gourmets' and gastronomic critics and their influence face to face to the media; the publicity and editorial fields, cooks and restaurateurs, touristic operators, etc. - who, from their own professional spheres, have contributed and still contribute to this fact as well, inside a general social process that does not seem to be, at least in the near future, drawing to an end.

\section{The Mediterranean diet as an outstanding sustainable resource}

In a now very well known paper, Gusssow and Clancy ${ }^{(7)}$ suggested the term 'sustainable diet' to describe a diet based on food chosen regarding not only health, but also sustainability (it is, a certain capability of food maintenance into the foreseeable future). Gussow and Clancy ${ }^{(7)}$ concluded that consumers should, when possible, buy 
'locally produced foods', which is less energy intensive (transport) and supports the local and regional agriculture.

More recently, in 2008, the Report of the FAO Regional Conference for Europe made important statements about sustainable diets: 'that the goal of increased global food production, including biofuels, should be balanced against the need to protect biodiversity, ecosystems, traditional foods and traditional agricultural practices' (B Burlingame and S Dernini, unpublished results).

As pointed out at the beginning of this article, with modern agriculture and globalisation of foods, the concepts of the sustainable diet and human ecology have been neglected in favour of intensification and industrialisation of agricultural systems. More recently, the growing concern over food safety has motivated a renewed interest in organic foods ${ }^{(8)}$ and locally produced and sustainable foods, particularly in the Mediterranean area. Movements like 'Slow Food', born in Turin (Italy), are based on the defence of local productions, biodiversity and sustainability, where both socio-cultural and biological aspects are included:

'Slow Food is a non-profit, eco-gastronomic membersupported organization that was founded in 1989 to counteract fast food and fast life, the disappearance of local food traditions and people's dwindling interest in the food they eat, where it comes from, how it tastes and how our food choices affect the rest of the world. To do that, Slow Food brings together pleasure and responsibility, and makes them inseparable ${ }^{(9)}$.

As every food system in its own biosocial context, the Mediterranean diet is an outstanding resource, yet it has not been fully acknowledged and enhanced within the Euro-Mediterranean partnership ${ }^{(10)}$, for the achievement of effective sustainable development in the Mediterranean, as was pointed out in the report Mediterranean Strategy on Sustainable Development, issued in 2005 by the United Nations Environment Programme:

'Mediterranean agricultural and rural models, which are at the origins of Mediterranean identity, are under increasing threat from the predominance of imported consumption patterns. This trend is illustrated in particular by the decline of the Mediterranean dietary model despite the recognized positive effects on health. The prospective scenario for the expected impacts of trade liberalization, climate change and the lack of efficient rural policies offers a gloomy picture in some southern and eastern Mediterranean countries, with the prospect of aggravated regional imbalances, deeper ecological degradation and persistent or accrued social instability... . Create a conducive regional environment to help countries develop policies and efficient procedures for the labelling and quality certification of Mediterranean food products and to promote the Mediterranean diet ${ }^{(11)}$.
In this sense, and as Akkelidou ${ }^{(12)}$ points out regarding the Mediterranean area, 'Current agricultural and trade policies are inappropriate (...). Thus, it is imperative to reform them to ensure the quality, safety and availability of food, as well as the sustainability of production, resources and the environment'.

\section{Conclusions}

In short, the consumer is moving further and further away from the processes used to produce the food he eats, foodstuffs that are treated in industrial processes that are beyond his influence and in many cases his understanding. Consumers are becoming increasingly unhappy with such processes and are looking instead for produce they believe to be 'natural', 'healthy' and 'traditional'. In doing so, they are trying to regain their control over and confidence in the food they eat.

In this context (and as every food system in its own biosocial context), the Mediterranean diet is an outstanding resource - locally produced in culturally coherent contexts - for the Mediterranean area.

While good nutrition should be a goal of agriculture, it is imperative that concerns over sustainability are not lost in the process. Many dietary patterns can be healthy, but they can vary substantially in terms of their resource cost. The Mediterranean diet has been characterised, analysed and promoted through a variety of methods within a number of scientific and applied disciplines (Burlingame and Dernini, unpublished results). It continues to be recognised and appreciated as a sustainable and culturally coherent diet in the Mediterranean region. In this framework, the recent recognition in November 2010 of the Mediterranean diet as a World Immaterial Heritage by UNESCO can be an important future challenge for Mediterranean local food production and manufacture. However, this major challenge involves a strong commitment to safeguarding and promotion that cannot be neglected. In this framework, the active role of the public sector is absolutely necessary.

\section{Acknowledgements}

The author declares that he has no conflict of interest. The author thanks Josep M Solé Sedeño, Joan Reguant, Sandro Dernini, Lluís Serra Majem and Anna Bach-Faig for their comments.

\section{References}

1. Food and Agricultural Organization of the United Nations (2010) Petition to end Hunger-1 Billion Hungry Campaign. http://www.fao.org/getinvolved/petitiontoendhunger/en/ (accessed March 2011).

2. Medina FX (2003) Consumo de carne y crisis alimentarias en España. In Cuadernos del CEAgro, no. 4, pp. 101-109. Buenos Aires: Centro de Estudios del Sistema Agroalimentario. 
Facultad de Ciencias Agrarias. Universidad Nacional de Lomas de Zamora.

3. Contreras J, Riera A \& Medina FX (2005) Introducción. In Sabores del Mediterráneo. Aportaciones para la promoción de un patrimonio alimentario común, pp. 14-22 [J Contreras, A Riera and FX Medina, editors]. Barcelona: European Institute of the Mediterranean.

4. Mintz S (1996) Tasting Food, Tasting Freedom. Incursions into Eating, Culture and the Past. Boston, MA: Beacon Press.

5. Medina FX (1998) Mediterranean food: the return of tradition. Rivista di Antropologia 76, Suppl. 1, 343-351.

6. Schlosser E (2001) Fast Food Nation: The Dark Side of the All-American Meal. New York, NY: Houghton Mifflin.

7. Gussow JD \& Clancy KL (1986) Dietary guidelines for sustainability. $J$ Nutr Educ 18, 1-5.

8. Herrin M \& Gussow JD (1989) Designing a sustainable regional diet. J Nutr Educ 21, 270-275.

9. Petrini C (2010) Slow food. http://www.slowfood.com/ (accessed February 2011).
10. Dernini S (2008) The strategic proposal to candidate the Mediterranean Diet for inscription in the UNESCO List of Intangible Cultural Heritage. In Med.2008. Mediterranean Yearbook. 2007 in the Euro-Mediterranean Space, pp. 288-291. Barcelona: European Institute of the Mediterranean and Fundació CIDOB.

11. UNEP/MAP (2005) Mediterranean strategy for sustainable development: a framework for environmental sustainability and shared prosperity. 14th Ordinary Meeting of the Contracting Parties to the Convention for the Protection of the Marine Environment and the Coastal Region of the Mediterranean and its Protocols, Athens. http://www. planbleu.org/publications/smdd_uk.pdf (accessed February 2011).

12. Akkelidou D (2009) Food Security in the Euro-Mediterranean Area: Main Challenges. Barcelona: European Institute of the Mediterranean; available at http://www.iemed.org/activitats/ 2010/Observatori/Dina_Akkelidou.pdf 